\title{
Parthenolide treatment activates stress signaling proteins in high-risk acute lymphoblastic leukemia cells with chromosomal translocation $t(4 ; 11)$
}

\author{
SUSAN J. ZUNINO ${ }^{1}$, DAVID H. STORMS ${ }^{1}$ and JONATHAN M. DUCORE ${ }^{2}$ \\ ${ }^{1}$ United States Department of Agriculture, Agricultural Research Service, Western Human Nutrition Research Center, \\ 430 West Health Sciences Drive, University of California, Davis, CA 95616; ${ }^{2}$ Department of Pediatrics, \\ Section of Hematology/Oncology, University of California School of Medicine, \\ 2516 Stockton Blvd., Sacramento, CA 95817, USA
}

Received July 9, 2010; Accepted August 20, 2010

DOI: 10.3892/ijo_00000782

\begin{abstract}
Parthenolide, the principal bio-active component of the herb feverfew (Tanacetum parthenium), has shown antileukemic activity. We evaluated the cell cycle status and the phosphorylation/activation of proteins involved in signal transduction in $\mathrm{t}(4 ; 11)$ and non- $\mathrm{t}(4 ; 11)$ acute lymphoblastic leukemia (ALL) cell lines after treatment with parthenolide. The cells were treated with the vehicle or $10 \mu \mathrm{M}$ parthenolide for 2, 4, 6 and $8 \mathrm{~h}$. As shown by flow cytometric analysis, parthenolide induced growth arrest at the $\mathrm{S}$ to $\mathrm{G} 2 / \mathrm{M}$ phase transition. Using multiplex technology and Western blotting, we showed that the treatment with parthenolide within 0 to $10 \mathrm{~h}$ induced the phosphorylation of stress signaling proteins, including the p38 mitogen-activated protein kinase, the c-Jun $\mathrm{N}$-terminal kinase, c-Jun, the heat shock protein 27 and protein kinase $\mathrm{B}$. These data show that parthenolide induces a stress response leading to cell death and provide further evidence suggesting that parthenolide could be useful as a novel therapeutic agent against high risk ALL with chromosomal translocation $\mathrm{t}(4 ; 11)$.
\end{abstract}

\section{Introduction}

Parthenolide, a sesquiterpene lactone, is the principal bioactive component of the medicinal herb feverfew (Tanacetum parthenium) (1). Feverfew has been used in folk medicine to treat fever, migraines, inflammation, stomach ache, toothache, menstrual irregularities, and rheumatoid arthritis (2-5). Parthenolide has also shown anti-cancer activities (6). The

Correspondence to: Dr Susan J. Zunino, United States Department of Agriculture, Western Human Nutrition Research Center, 430 West Health Sciences Drive, University of California, Davis, CA 95616, USA

E-mail: susan.zunino@ars.usda.gov

Key words: parthenolide, acute lymphoblastic leukemia, signal transduction, stress response potent anti-cancer activity of this substance is due in part to its ability to inhibit the transcription factor NF- $\mathrm{B}$, thereby reducing the survival potential of a number of cancer cells (6-8). Furthermore, the parthenolide-induced generation of reactive oxygen species (ROS) in cancer cells plays a key role in promoting apoptotic cell death $(9,10)$.

The chromosomal translocation $\mathrm{t}(4 ; 11)(\mathrm{q} 21 ; \mathrm{q} 23)$ is found in $60-85 \%$ of infants, $2 \%$ of children, and $3-6 \%$ of adults diagnosed with acute lymphoblastic leukemia (ALL) and the presence of this chromosomal abnormality is strongly associated with poor prognosis $(11,12)$. This type of leukemia is deemed a high-risk subgroup of ALL and is highly resistant to conventional chemotherapeutics, necessitating further research to find potential novel therapeutic agents. We previously reported that parthenolide effectively induced apoptotic cell death in SEM and RS4;11 cell lines established from patients with ALL carrying the $\mathrm{t}(4 ; 11)(\mathrm{q} 21 ; \mathrm{q} 23)$ chromosomal translocation (13). Compared to the REH leukemia cells which have no translocation, parthenolide killed the $\mathrm{t}(4 ; 11)$ ALL cells more rapidly at a lower concentration. Cell death in these leukemic cells was accompanied by increases in multiple ROS, including nitric oxide, superoxide anion and hypochlorite anion (13).

In the present study, we examined the early intracellular protein signaling events leading to parthenolide-induced apoptosis in these leukemia cells. Parthenolide treatment induced activation (phosphorylation) of several proteins involved in the stress response, including the heat shock protein 27 (HSP27), protein kinase B (Akt), c-Jun N-terminal kinase (JNK), c-Jun and the p38 mitogen-activated protein kinases (p38 MAPK). These data demonstrate part of the mechanism by which parthenolide induces cell death in $\mathrm{t}(4 ; 11)$ and non-t $(4 ; 11)$ ALL cells, and provide further information suggesting that this phytochemical could be useful as a novel therapeutic agent against ALL.

\section{Materials and methods}

Cell lines and reagents. SEM and RS4;11 are established cell lines from patients diagnosed with high-risk pre-B cell ALL containing the chromosomal translocation $\mathrm{t}(4 ; 11)(\mathrm{q} 21 ; \mathrm{q} 23)$ 
$(14,15)$. The REH cell line (pre-B cell ALL without the translocation) was obtained from the American Type Culture Collection (Manassas, VA). All the cell lines were maintained at $37^{\circ} \mathrm{C}, 5 \% \mathrm{CO}_{2}$ in RPMI-1640 (Invitrogen, Carlsbad, CA) supplemented with $10 \%$ fetal bovine serum (Sigma, St. Louis, MO), $50 \mathrm{IU} / \mathrm{ml}$ penicillin, $50 \mu \mathrm{g} / \mathrm{ml}$ streptomycin, $0.25 \mu \mathrm{g} / \mathrm{ml}$ amphotericin $\mathrm{B}, 1 \mathrm{mM}$ sodium pyruvate and $2 \mathrm{mM}$ L-glutamine (Invitrogen). For each experiment, the cells were split to a density of $0.5 \times 10^{6} / \mathrm{ml}$ before treatment.

Parthenolide was purchased from EMD Biosciences (San Diego, CA) and stock solutions were dissolved in dimethylsulfoxide (DMSO; Sigma). As a control, an equivalent amount of DMSO was added to a control cell population in each experiment.

Cell cycle analysis. The leukemia cells were treated with DMSO or $10 \mu \mathrm{M}$ parthenolide and collected for cell cycle analysis at 2, 4, 6, and $8 \mathrm{~h}$. Parthenolide and the vehicle were left in the medium during the entire treatment period. The cell cycle was measured at each time-point by lysing the cells in a hypotonic solution containing $1 \mathrm{mg} / \mathrm{ml}$ sodium citrate, $0.1 \%$ Triton $\mathrm{X}-100$, and $50 \mu \mathrm{g} / \mathrm{ml}$ propidium iodide (PI, Sigma) and analyzing the resulting nuclei using a FACSCanto fluorescence-activated cell sorter (FACS) with FACSDiva software (Becton-Dickinson, San Jose, CA). Twenty thousand events were collected for each sample stained with PI. The cell cycle profiles were generated with the flow cytometry data of the PI-stained nuclei using ModFit LT software (Verity Software House, Inc., Topsham, ME).

Multiplex measurements of phosphoproteins. The phosphorylation status of the proteins Akt, ERK1/2, JNK, p38 MAPK, c-Jun and HSP27 was assessed using the Bio-Plex Phosphoprotein Detection kit (Bio-Rad, Hercules, CA). The SEM, RS4;11 and REH cells were treated with $0.1 \%$ DMSO as the control or $10 \mu \mathrm{M}$ parthenolide, and the cell lysates were prepared at 2, 4, 6, 8 and $10 \mathrm{~h}$. Lysates were also prepared from untreated cells as a zero time-point. Cell lysates were prepared from $2.5 \times 10^{6}$ cells at each time-point with lysate buffer supplied with the kit according to manufacturer's instructions with the following exceptions: i) The cells were pelleted, then washed with $0.5 \mathrm{ml}$ wash buffer, ii) the proteinase inhibitor Pefabloc SC (Roche Diagnostics, Indianapolis, IN) was substituted for phenylmethanesulphonyl fluoride in the lysis buffer and used at a concentration of $2 \mathrm{mM}$, and iii) the cells were suspended in $200 \mu \mathrm{l}$ lysis buffer and freeze/ thawed once before agitation for $20 \mathrm{~min}$ at $4^{\circ} \mathrm{C}$. Protein concentrations for each lysate were measured using the BioRad DC Protein Assay. Bovine $\gamma$-globulin was used as the standard for the protein measurements. Lysate samples and supplied lysate controls were analyzed in duplicate on a BioPlex multiplex flow cytometry instrument (Bio-Rad) following the phosphoprotein detection kit instructions except that 50 beads were acquired per bead region instead of 25 . The data were expressed as the means of the median bead intensities normalized to the protein concentration in each well.

Western blot analysis of total and phosphoproteins. For further analysis of the protein levels of the total protein and phosphorylation status after DMSO or $10 \mu \mathrm{M}$ parthenolide treatment, protein lysates were prepared by vortexing $1 \times 10^{8}$ cells per $\mathrm{ml}$ of lysis buffer containing $1 \%$ Triton $\mathrm{X}-100$ (Sigma), $50 \mathrm{mM}$ Tris- $\mathrm{Cl}, \mathrm{pH} 8.0,150 \mathrm{mM} \mathrm{NaCl}$, and the following proteinase inhibitors: aprotinin, leupeptin, EDTA (Sigma) and Pefabloc SC (Roche Diagnostics). Protein concentrations were measured using the Bio-Rad DC Protein Assay. Equal amounts of protein $(40 \mu \mathrm{g})$ were electrophoresed on $10 \%$ SDS-polyacrylamide gels under reducing conditions and electroblotted on to PVDF membranes (GE Healthcare, Piscataway, NJ). The blocking and staining of membranes were carried out using Tris-buffered saline containing 5\% bovine serum albumin, Fraction V (Sigma) and 0.1\% Tween-20 (Sigma). Rabbit polyclonal antibodies against phosphorylated and total Akt, p38 MAPK, JNK, c-Jun, phosphorylated HSP27 and mouse antibody against total HSP27, were purchased from Cell Signaling Technology (Danvers, MA) and used according to the manufacturer's instructions. HRP-conjugated donkey anti-rabbit and sheep anti-mouse IgGs (GE Healthcare) were used as secondary antibodies at a dilution of 1:1000. The ECL Western blotting system (GE Healthcare) was used for the visualization of immunoreactive bands at the concentrations suggested by the manufacturer.

Statistical analysis. All the statistical analyses were performed with GraphPad software (GraphPad Software, Inc., San Diego, CA) and the data were displayed as arithmetic means \pm SEM. For analysis of the cell cycle and Bio-Plex data, two-way analysis of variance (ANOVA) with Bonferroni post-hoc tests was used to determine the differences in the cell cycle profiles and in the relative levels of phosphoproteins over time between the DMSO- and parthenolide-treated cells. The confidence interval for significant differences was set at $95 \%$.

\section{Results}

Parthenolide induces cell cycle arrest. In previous studies, we found that $10 \mu \mathrm{M}$ parthenolide was a potent inducer of apoptosis in $\mathrm{t}(4 ; 11)$ ALL-derived cell lines. In this study, we examined the early events leading to apoptosis after parthenolide treatment by first evaluating whether parthenolide influenced the cell cycle in these leukemic cells prior to the induction of apoptosis. The cells were treated with DMSO or $10 \mu \mathrm{M}$ parthenolide and the cell cycle changes were measured at 2, 4, 6 and $8 \mathrm{~h}$ after treatment. Fig. 1 shows that the cells were arrested at the $\mathrm{S}$ to G2/M transition of the cell cycle by parthenolide treatment in the SEM and REH cells within $4 \mathrm{~h}$ and in the RS4;11 cells within $8 \mathrm{~h}$. This is evident by an accumulation of cells in the $\mathrm{S}$ phase and a reduction of cells in $\mathrm{G} 2 / \mathrm{M}$. At $8 \mathrm{~h}$ post-parthenolide treatment, the SEM cells were undergoing cell death and this was displayed by an accumulation of cells in the subG1 population (Fig. 2). An increase in cells in the G1 phase was observed at this timepoint for SEM and this was possibly due to the progressive loss of $4 \mathrm{~N}$ DNA resulting in a mixture of signals in the $2 \mathrm{~N}$ G1 population. Therefore, this increase was not considered a parthenolide-induced G1 arrest. No subG1 population was detected for the other time-points for any cell line, other than the 8-h time-point for SEM. 
SEM 2h
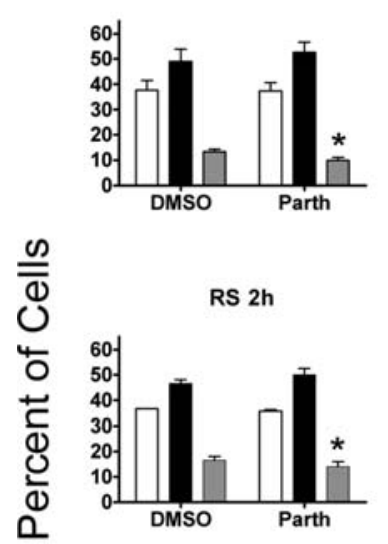

REH 2h

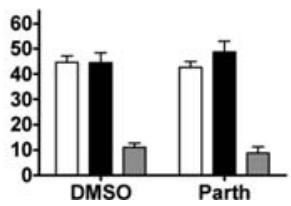

SEM 4h

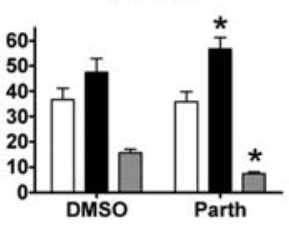

RS 4h

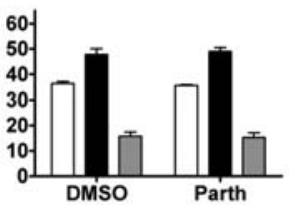

REH 4h

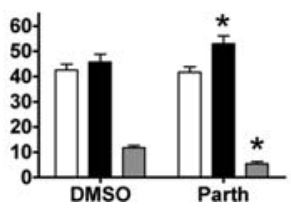

SEM 6h

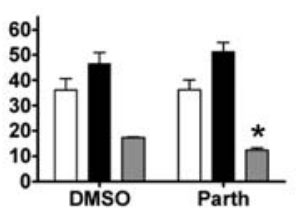

RS $6 h$

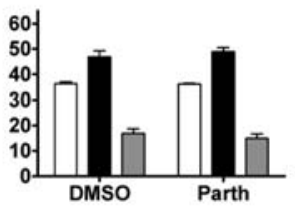

REH 6h

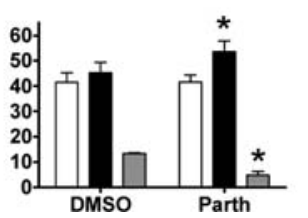

SEM 8h

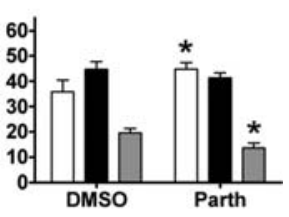

RS $8 \mathrm{~h}$

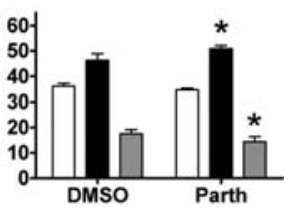

REH 8h

Figure 1. Parthenolide treatment induces cell cycle arrest. SEM, RS4;11 and REH cells were treated with DMSO (control) or $10 \mu \mathrm{M}$ parthenolide for $2,4,6$ and $8 \mathrm{~h}$, and cells were lysed in hypotonic buffer containing PI. The resulting nuclei were collected on a flow cytometer and the percentage of cells in the G1 (white bars), S (black bars) and G2/M (grey bars) phases of the cell cycle were calculated using ModFit LT software. The data represent 3 separate experiments. The asterisks represent the significant differences compared to the control cells for each cell cycle stage $(\mathrm{P}<0.05)$.

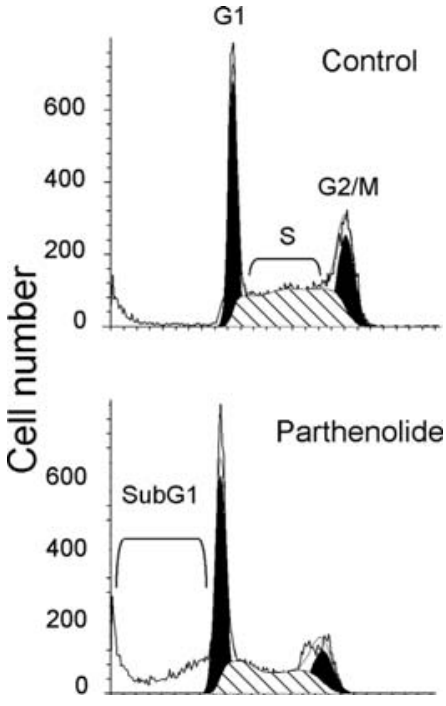

Figure 2. Cell cycle analysis of SEM cells at $8 \mathrm{~h}$ post-treatment with parthenolide. SEM cells were treated with DMSO (control) or $10 \mu \mathrm{M}$ parthenolide for $8 \mathrm{~h}$ and lysed in hypotonic buffer containing PI. Cell cycle histogram profiles were generated with ModFit LT software. The subG1, G1, S and $\mathrm{G} 2 / \mathrm{M}$ populations are indicated. The data are representative of 3 experiments.

Parthenolide treatment activates stress response proteins. We then analyzed signal transduction pathways in order to determine the early signaling events leading to parthenolideinduced apoptosis in leukemic cells. Multiplex technology was used to evaluate multiple proteins simultaneously from single samples. The activation of proteins involved in signal transduction was determined by measuring the phosphorylation status of each protein at $0,2,4,6,8$ and $10 \mathrm{~h}$ post- treatment with parthenolide or DMSO. Several proteins directly involved in the cellular stress response leading to apoptosis were phosphorylated. The levels of phosphorylated p38 MAPK were increased in all 3 lines compared to the control cells and the differences between the treatment groups were significant at each time-point $(\mathrm{P}<0.05$; Fig. $3 \mathrm{~A})$. The level of phosphorylated JNK was greatest in the SEM and RS4;11 cells $(\mathrm{P}<0.05$; Fig. 3B). The differences in phosphorylated JNK between the treatment groups were significant in the REH cells, but the detectable levels remained low compared to the SEM and RS4;11 cells. Phosphorylated c-Jun levels were also elevated in the parthenolide-treated compared to the control cells for all 3 lines $(\mathrm{P}<0.05$; Fig. 3C). Significant signals for phosphorylated p38MAPK, JNK and c-Jun were sustained throughout the 10-h time period after parthenolide treatment, indicating that the treatment with parthenolide maintained stress on the leukemia cells.

The proteins HSP27 and Akt are considered survival proteins and the activation of these proteins in response to parthenolide treatment, was also analyzed. An increase in phosphorylated HSP27 was observed in the SEM cells during the first $6 \mathrm{~h}$ of treatment with parthenolide, with a reduction in the phosphorylated form occurring within $8 \mathrm{~h}$ after treatment $(\mathrm{P}<0.05$; Fig. 4A). RS4;11 showed the largest increase in the phosphorylation of HSP27 after the treatment with parthenolide and the phosphorylation was maintained for at least $10 \mathrm{~h}$ after treatment. It should be noted that even though the differences between the treatment groups was significant in the REH cells, the signal for phosphorylated HSP27 in these cells was exceedingly low compared to the signal in the SEM and RS4;11 cells, as indicated by the y-axis values. The phosphorylation status of Akt was also variable between the 3 


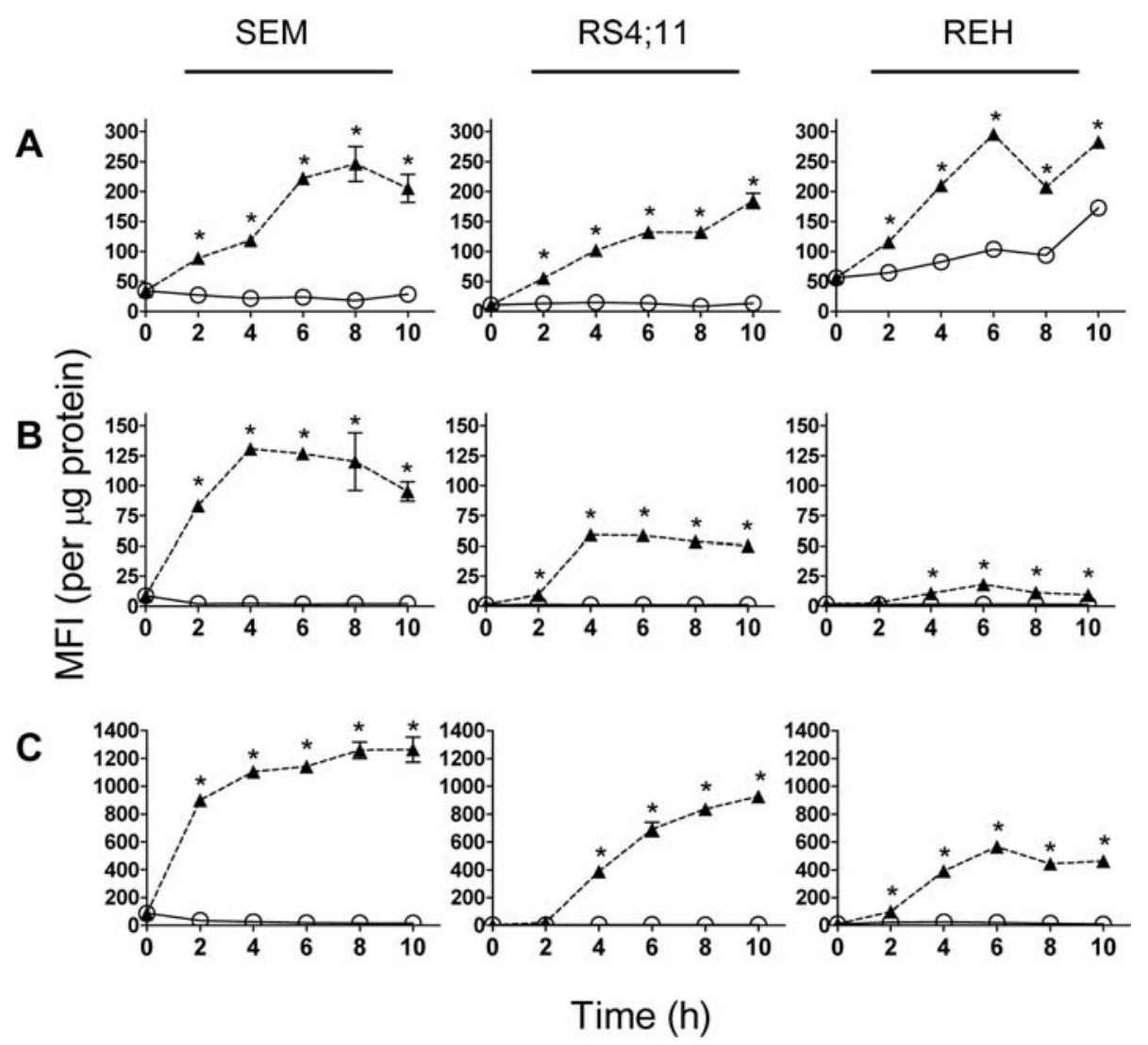

Figure 3. Stress proteins are phosphorylated after treatment with parthenolide. SEM, RS4;11 and REH cells were treated with DMSO (control) or $10 \mu$ M parthenolide for 2, 4, 6, 8 and $10 \mathrm{~h}$. Cell lysates were prepared and run in duplicate on a Bio-Plex multiplex instrument. Lysates were analyzed for phosphorylated A) p38 MAPK, B) JNK and C) c-Jun. The data are expressed as the means of the median bead intensities normalized to the protein concentration in each well. MFI, mean fluorescent intensity. The asterisks represent the significant differences compared to the control cells for each timepoint $(\mathrm{P}<0.05)$.

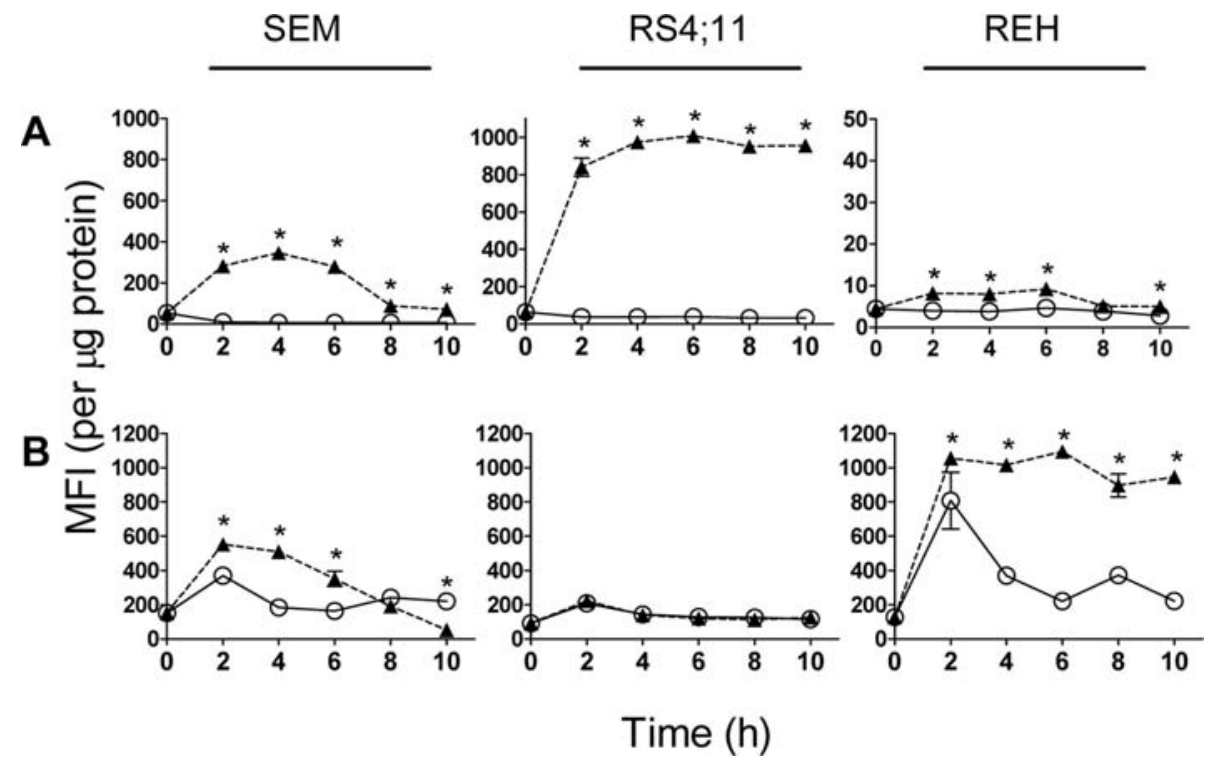

Figure 4. Protective proteins are phosphorylated after treatment with parthenolide. SEM, RS4;11 and REH cells were treated with DMSO (control) or $10 \mu \mathrm{M}$ parthenolide for 2, 4, 6, 8 and $10 \mathrm{~h}$. Cell lysates were prepared and run in duplicate on a Bio-Plex multiplex instrument. Lysates were analyzed for phosphorylated A) HSP27 and B) Akt. The data are expressed as the means of the median bead intensities normalized to the protein concentration in each well. MFI, mean fluorescent intensity. The asterisks represent the significant differences compared to the control cells for each time-point $(\mathrm{P}<0.05)$.

cell lines (Fig. 4B). Significant phosphorylation and activation of Akt occurred in the SEM and REH cells after the treatment with parthenolide compared to the control cells $(\mathrm{P}<0.05)$.
However, no changes in the phosphorylation status of Akt was observed in the RS4;11 cells between the 2 treatment groups. 


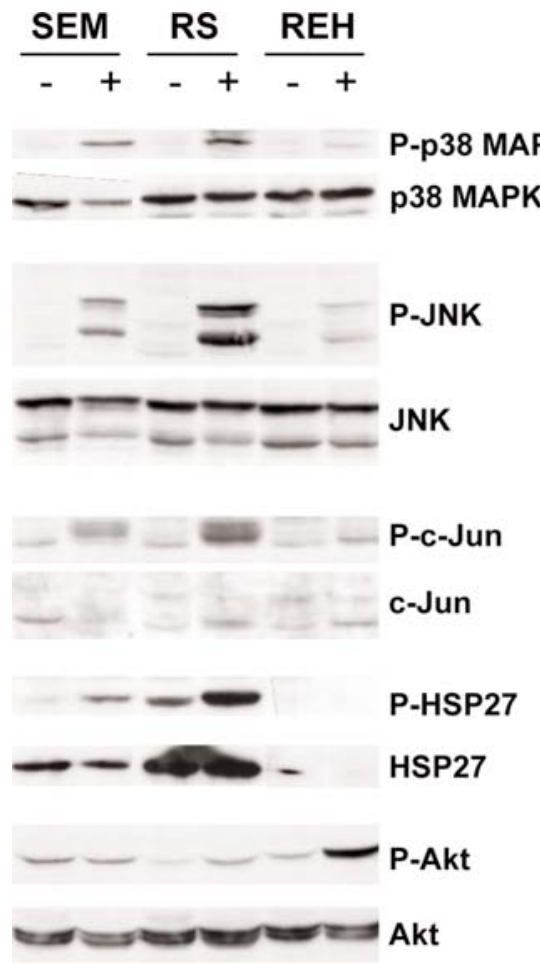

Figure 5. Western blot analysis of the phosphorylated and total proteins. SEM, RS4;11 and REH cells were treated with DMSO (control) or $10 \mu \mathrm{M}$ parthenolide for 4 and $10 \mathrm{~h}$. Cell lysates were prepared and equal amounts of proteins $(40 \mu \mathrm{g})$ were electrophoresed on $10 \%$ SDS-polyacrylamide gels under reducing conditions, and electroblotted on to PVDF membranes. The blots were stained with rabbit polyclonal antibodies against phosphorylated and total p38 MAPK, JNK, c-Jun, Akt, phosphorylated HSP27 and mouse antibody against total HSP27. HRP-conjugated secondary antibodies and the ECL Western blotting system were used to visualize the bands. The lysates used were from 10-h treatments, except for the SEM cells stained with HSP27 and Akt, which were from the 4-h time-point. For each protein, the upper panel represents the phosphorylated protein, and the bottom panel represents the total protein. For each cell line: (-) Untreated; (+) parthenolide-treated.

Confirmation of phosphorylation status by Western blot analysis. Western blot analysis was performed in order to confirm the phosphorylation status of the above-mentioned proteins and to compare the total proteins after DMSO or $10 \mu \mathrm{M}$ parthenolide treatment (Fig. 5). Lysates represented the 10-h time-point except for HSP27 and Akt in the SEM cells, which were taken at the 4-h time-point based on the multiplex analyses. An increase in the phosphorylated p38 MAPK protein (Thr180/Tyr182) was detectable in all 3 cell lines, with the lowest signal observed in the REH cells. Two isoforms of JNK (46 and $54 \mathrm{kD}$ ) were observed and an increase in phosphorylated JNK (Thr183/Tyr185) was observed in the 3 lines after the treatment with parthenolide. Two isoforms of total c-Jun (43 and $48 \mathrm{kD}$ ) were expressed in the 3 lines and an increase in phosphorylated c-Jun (Ser63) was presented in the cells treated with parthenolide. Phosphorylated HSP27 (Ser78) was present in the lysates from the SEM and RS4;11 cells, but not in the REH cells after the treatment with parthenolide. The levels of phosphorylated Akt were increased in the REH cells, but only slightly in the SEM and RS4;11 lysates after the treatment with parthenolide. These data agree with the multiplex data, except for the phosphorylated p38 MAPK in the REH cells, where multiplex data showed a significant increase in phosphorylated protein similar to the signals obtained from the SEM and RS4;11 cells.

\section{Discussion}

These data show that treatment with parthenolide induces growth arrest and stress signaling responses in $\mathrm{t}(4 ; 11)$ ALL lines, as well as ALL cells without the chromosomal translocation. Parthenolide induced an arrest in the $S$ to $G 2 / M$ transition in all 3 cell lines within $8 \mathrm{~h}$ after treatment. Other studies have also reported a transient G2/M arrest in HL60 myeloid and Jurkat T-cell leukemia lines after treatment with parthenolide (16). The activation of p38 MAPK has been shown to induce $\mathrm{G} 2 / \mathrm{M}$ arrest in response to DNA damage (17-19). The arrest of cells in G2/M by p38 MAPK was shown to occur by at least 2 mechanisms: i) By the p38 MAPK-induced activation of the tumor suppressor protein p53 leading to a p53-dependent G2/M arrest. The activation of p53 leads to the transcription of p21, the growth arrest and DNA damage $45 \alpha$ and 14-3-3 proteins resulting in the downstream association with and inactivation of the mitotic cyclin $\mathrm{B} / \mathrm{Cdc} 2$ complex. ii) By phosphorylating and inactivating the $\mathrm{Cdc} 25 \mathrm{~B}$ phosphatase required to activate the cyclin $\mathrm{B} / \mathrm{Cdc} 2$ complex so that cells can progress through mitosis (17). The phosphorylation and dephosphorylation of the cyclin $\mathrm{B} / \mathrm{Cdc} 2$ protein complex regulate the transition of cells through mitosis $(20,21)$. Specialized Cdc25 phosphatases are key players in the regulation of the phosphorylation and activation status of the cyclin B/Cdc2 complex $(22,23)$. Although we did not test for DNA damage, the formation of high molecular weight fragments of $\sim 700,300$ and $50 \mathrm{kbp}$ correlates with the early chromatin alterations displayed in pre-apoptotic cells $(24,25)$. In our previous studies, we showed that parthenolide induced the generation of significant levels of ROS in leukemia cells within the first $4 \mathrm{~h}$ of treatment (13), which can lead to damaged DNA and subsequent growth arrest (26). The activation of p38 MAPK by parthenolide in SEM, RS4;11 and REH cells could be a product of the parthenolide-induced generation of ROS in these cells.

The treatment of leukemic cells in our study resulted in the phosphorylation of JNK and c-Jun. The JNK signaling pathway plays a major role in apoptosis (27). JNK has been shown to translocate to the mitochondria and influence mitochondrial-mediated apoptosis $(28,29)$. Parthenolide induces mitochondrial-mediated apoptosis in the leukemia cell lines (13), possibly through the action of activated JNK. JNK has also been shown to inactivate the anti-apoptotic proteins, $\mathrm{Bcl}-2$ and $\mathrm{Bcl}-\mathrm{XL}$, and to enhance the activation of the proapoptotic proteins, Bad, Bim and Bax (29-33). In a previous study, we showed that REH cells were less sensitive to the induction of apoptosis by parthenolide than the SEM and RS4;11 cells (13). REH cells required $25 \mu \mathrm{M}$ parthenolide in order to induce the equivalent level of death observed in the SEM and RS4;11 cells treated with $10 \mu \mathrm{M}$ parthenolide. In the current study, the parthenolide-induced phosphorylation of JNK and c-Jun was reduced in the REH cells compared to that observed in the SEM and RS4;11 cells. These data suggest that the activation of the JNK signaling pathway is an important event for inducing the more rapid apoptotic death seen in the $t(4 ; 11)$ ALL lines. 
HSP27 is a member of the small heat shock protein family and has multiple functions (34). The activation of HSP27 is induced in the cells by many types of environmental stress including heat shock, inflammatory cytokines and oxidants, and plays a protective role (35). HSP27 has been shown to inhibit stress-induced apoptosis by binding to apoptogenic cytochrome $\mathrm{c}$ after release from the mitochondria and the interference with downstream caspase activation $(36,37)$. HSP27 inhibits the activation of the pro-apoptotic protein Bax (38). HSP27 has also been shown to inhibit apoptosis by the direct interaction and activation of Akt (39). The phosphorylation and activation of HSP27 occurred within the first $2 \mathrm{~h}$ after the parthenolide treatment of SEM and RS4;11. The SEM cells had elevated levels of both phosphorylated HSP27 and Akt. However, the RS4;11 cells had increased levels of phosphorylated HSP27, but no activation of Akt above the control levels, and the REH cells showed low levels of phosphorylated HSP27, but significant levels of phosphorylated Akt. Furthermore, SEM and RS4;11 were more sensitive to parthenolide-induced apoptosis. Therefore, the importance of HSP27 and Akt activation as possible protective events in response to parthenolide treatment, is not clear.

The stimulation of conflicting pathways promoting and protecting from apoptosis provides a system for investigating the roles of these stress proteins in apoptotic and/or survival signaling. These data provide further evidence for the potential of parthenolide as a novel therapeutic and show at least part of the mechanism of parthenolide-induced apoptosis in ALL cells. Further evaluation in animal models is required in order to evaluate the bioavailability and efficacy of parthenolide against high-risk leukemia in vivo.

\section{Acknowledgements}

This study was funded by grants from the St. Baldrick's Foundation to J.M.D. and the United States Department of Agriculture, CRIS project (no. 5306-51530-013-00D) to S.J.Z. and D.H.S.

\section{References}

1. Knight DW: Feverfew: chemistry and biological activity. Nat Prod Rep 12: 271-276, 1995.

2. Johnson ES, Kadam NP, Hylands DM and Hylands PJ: Efficacy of feverfew as prophylactic treatment for migraine. Br Med J 31: 569-573, 1985 .

3. Biggs MJ, Johnson ES, Persaud NP and Ratcliffe DM: Platelet aggregation in patients using feverfew for migraine. Lancet 2 : $776,1982$.

4. Hall ICH, Lee KH, Starnes CO, Sumida Y, Wu RY, Waddell TG, Cochran JW and Gerhart KG: Anti-inflammatory activity of sesquiterpene lactones and related compounds. J Pharm Sci 68: 537-542, 1979

5. Jain NK and Kulkarni SK: Antinociceptive and anti-inflammatory effects of Tanacetum parthenium L. extract in mice and rats. $\mathbf{J}$ Ethnopharmacol 68: 251-259, 1999.

6. Pajak B, Gajkowska B and Orzechowski A: Molecular basis of parthenolide-dependent proapoptotic activity in cancer cells. Folia Histochem Cytobiol 46: 129-135, 2008.

7. Hehner SP, Hofmann TG, Dröge W and Schmitz ML: The antiinflammatory sesquiterpene lactone parthenolide inhibits NF-kappa B by targeting the I kappa B kinase complex. J Immunol 163: 5617-5623, 1999.

8. Garcia-Pineres AJ, Castro V, Mora G, Schmidt TJ, Strunck E, Pahl HL and Merfort I: Cysteine 38 in p65/NFkappaB plays a crucial role in DNA binding inhibition by sesquiterpene lactones. J Biol Chem 276: 39713-39720, 2001.
9. Wen J, You K-R, Lee S-Y, Song CH and Kim DG: Oxidative stress-mediated apoptosis, the anticancer effect of the sesquiterpene lactone parthenolide. J Biol Chem 277: 38954-38964, 2002.

10. Wang W, Adachi M, Kawamura R, Sakamoto H, Hayashi T, Ishida T, Imai K and Shinomura Y: Parthenolide-induced apoptosis in multiple myeloma cells involves reactive oxygen species generation and cell sensitivity depends on catalase activity. Apoptosis 11: 2225-2235, 2006.

11. Faderl S, Kantarjian HM, Talpaz M and Estrov Z: Clinical significance of cytogenetic abnormalities in adult acute lymphoblastic leukemia. Blood 91: 3995-4019, 1998.

12. Greaves MF and Wiemels J: Origins of chromosome translocations in childhood leukaemia. Nat Rev Cancer 3: 639-649, 2003.

13. Zunino SJ, Ducore JM and Storms DH: Parthenolide induces significant apoptosis and production of reactive oxygen species in high-risk pre-B leukemia cells. Cancer Lett 254: 119-127, 2007.

14. Greil J, Gramatzki M, Burger R, Marschalek R, Peltner M, Trautman U, Hansen-Hagge TE, Bartram CR, Fey GH, Stehr K and Beck J: The acute lymphoblastic leukemia cell line SEM with $\mathrm{t}(4 ; 11)$ chromosomal rearrangement is biphenotypic and responsive to interleukin-7. Br J Haematol 86: 275-283, 1994.

15. Stong RC, Korsmeyer SJ, Parkin JL, Arthur DC and Kersey JH: Human acute leukemia cell line with the $t(4 ; 11)$ chromosomal rearrangement exhibits B lineage and monocytic characteristics. Blood 65: 21-31, 1985.

16. Pozarowski P, Halicka DH and Darzynkiewicz Z: Cell cycle effects and caspase-dependent and independent death of HL-60 and Jurkat cells treated with the inhibitor of NF-kappaB parthenolide. Cell Cycle 2: 377-383, 2003.

17. Bulavin DV, Higashimoto Y, Popoff IJ, Gaarde WA, Basrur V, Potapova O, Appella E and Fornace AJ: Initiation of a G2/M checkpoint after ultraviolet radiation requires p38 kinase. Nature 411: 102-107, 2001.

18. Bulavin DV, Amundson SA and Fornace AJ: P38 and Chk1 kinases: different conductors for the $\mathrm{G}(2) / \mathrm{M}$ checkpoint symphony. Curr Opin Genet Dev 12: 92-97, 2002.

19. Mikhailov A, Shinohara M and Rieder CL: Topoisomerase II and histone deacetylase inhibitors delay the G2/M transition by triggering the p38 MAPK checkpoint pathway. J Cell Biol 166: $517-526,2004$.

20. Lundgren K, Walworth N, Booher R, Dembski M, Kirschner M and Beach D: Mik1 and Wee1 cooperate in the inhibitory tyrosine phosphorylation of Cdc2. Cell 64: 1111-1122, 1991.

21. Parker LL, Atherton-Fessler S, Lee MS, Ogg S, Falk JL, Swenson KI and Piwnica-Worms H: Cyclin promotes the tyrosine phosphorylation of $\mathrm{p} 34^{\mathrm{cdc} 2}$ in a Wee ${ }^{1+}$ dependent manner. EMBO J 10: 1255-1263, 1991

22. Gautier J, Solomon MJ, Booher RN, Bazan JF and Kirschner MW: $\mathrm{Cdc} 25$ is a specific tyrosine phosphatase that directly activates p34cdc2. Cell 67: 197-211, 1991.

23. Strausfeld U, Labbe JC, Fesquet D, Cavadore JC, Picard A, Sadhu K, Russell P and Doree M: Dephosphorylation and activation of a p34 cdc2/cyclin B complex in vitro by human CDC25 protein. Nature 351: 242-245, 1991.

24. Brown DG, Sun XM and Cohen GM: Dexamethasone-induced apoptosis involves cleavage of DNA to large fragments prior to internucleosomal fragmentation. J Biol Chem 268: 3037-3039, 1993.

25. Sun XM and Cohen GM: $\mathrm{Mg}(2+)$-dependent cleavage of DNA into kilobase pair fragments is responsible for the initial degradation of DNA in apoptosis. J Biol Chem 269: 14857-14860, 1994.

26. Shackelford RE, Kaufman WK and Paules RS: Oxidative stress and cell cycle checkpoint function. Free Rad Biol Med 28: 1387-1404, 2000.

27. Cui J, Zhang M, Zhang Y and Xu Z: JNK pathway: diseases and therapeutic potential. Acta Pharmacol Sin 28: 601-608, 2007.

28. Tournier C, Hess P, Yang DD, Xu J, Turner TK, Nimnual A Bar-Sagi D, Jones SN, Flavell RA and Davis RJ: Requirement of JNK for stress-induced activation of the cytochrome cmediated death pathway. Science 288: 870-874, 2000

29. Kharbanda S, Saxena S, Yoshida K, Pandey P, Kaneki M, Wang Q, Cheng K, Chen YN, Campbell A, Sudha T, Yuan ZM, Narula J, Weichselbaum R, Nalin C and Kufe D: Translocation of SAPK/JNK to mitochondria and interaction with $\mathrm{Bcl}-\mathrm{x}(\mathrm{L})$ in response to DNA damage. J Biol Chem 275: 322-327, 2000. 
30. Maundrell K, Antonsson B, Magnenat E, Camps M, Muda M, Chabert C, Gillieron C, Boschert U, Vial-Knecht E, Martinou JC and Arkinstall S: Bcl-2 undergoes phosphorylation by c-Jun Nterminal kinase/stress-activated protein kinases in the presence of the constitutively active GTP-binding protein Rac1. J Biol Chem 272: 25238-25242, 1997.

31. Yamamoto K, Ichijo $\mathrm{H}$ and Korsmeyer SJ: BCL-2 is phosphorylated and inactivated by an ASK1/Jun N-terminal protein kinase pathway normally activated at G(2)/M. Mol Cell Biol 19: 8469-8478, 1999.

32. Donovan N, Becker EB, Konishi Y and Bonni A: JNK phosphorylation and activation of BAD couples the stress-activated signaling pathway to the clel death machinery. J Biol Chem 277: 40944-40949, 2002.

33. Lei K and Davis RJ: JNK phosphorylation of Bim-related members of the Bcl-2 family induces Bax-dependent apoptosis. Proc Natl Acad Sci USA 100: 2432-2437, 2003.

34. Arya R, Mallik M and Lakhota SC: Heat shock genes - integrating cell survival and death. J Biosci 32: 595-610, 2007.
35. Schmitt E, Gehrmann M, Brunet M, Multhoff G and Garrido C: Intracellular and extracellular functions of heat shock proteins: repercussions in cancer therapy. J Leukoc Biol 81: 15-27, 2007.

36. Bruey JM, Ducasse C, Bonniaud P, Ravagnan L, Susin SA, Diaz-Latoud C, Gurbuxani S, Arrigo AP, Kroemer G, Solary E and Garrido C: HSP27 negatively regulates cell death by interacting with cytochrome c. Nat Cell Biol 2: 645-652, 2000.

37. Garrido C, Bruey JM, Fromentin A, Hammann A, Arrigo AP and Solary E: HSP27 inhibits cytochrome c-dependent activation of procaspase-9. FASEB J 13: 2061-2070, 1999.

38. Havasi A, Li Z, Wang Z, Martin JL, Botla V, Ruchalski K, Schwartz JH and Borkan SC: HSP27 inhibits Bax activation and apoptosis via a phosphatidylinositol 3-kinase-dependent mechanism. J Biol Chem 283: 12305-12313, 2008.

39. Rane MJ, Pan Y, Singh S, Powell DW, Wu R, Cummins T, Chen Q, McLeish KR and Klein JB: Heat shock protein 27 control apoptosis by regulating Akt activation. J Biol Chem 278: 27828-27835, 2003. 